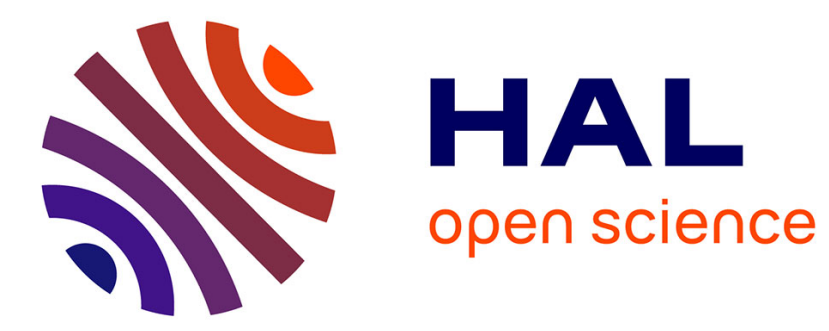

\title{
Temporal Orientation in Conditionals
}

Bridget Copley

\section{To cite this version:}

Bridget Copley. Temporal Orientation in Conditionals. Jacqueline Guéron et Jacqueline Lecarme.

Time and Modality, Springer, pp.59-77, 2009. halshs-00093528

\section{HAL Id: halshs-00093528 \\ https://shs.hal.science/halshs-00093528}

Submitted on 13 Sep 2006

HAL is a multi-disciplinary open access archive for the deposit and dissemination of scientific research documents, whether they are published or not. The documents may come from teaching and research institutions in France or abroad, or from public or private research centers.
L'archive ouverte pluridisciplinaire HAL, est destinée au dépôt et à la diffusion de documents scientifiques de niveau recherche, publiés ou non, émanant des établissements d'enseignement et de recherche français ou étrangers, des laboratoires publics ou privés. 


\title{
Temporal orientation in conditionals*
}

\author{
(Or, How I learned to stop worrying and love UFOs) \\ Bridget Copley \\ CNRS/Université Paris 8 \\ bcopley@bcopley.com
}

August 25, 2006

\begin{abstract}
This paper argues for a modal explanation for temporal orientation facts in both antecedents and consequents of conditionals. Futureoriented statives are shown to get their future orientation by means of a different mechanism from future-oriented eventives. Thus, eventuality type and temporal orientation turn out to be correlated more closely than previously thought, and the "present eventive constraint" is not useful in accounting for the temporal orientation facts. Thus we must look for a new kind of explanation. I argue that temporal orientation, and therefore also eventuality type, are correlated with modal flavor, so that the most promising way to explain the temporal orientation facts will be through appealing to the modal facts. Two apparent objections to this kind of account are removed: the proposed existence of epistemic eventives (I argue that these examples are actually derived statives), and the assumption that antecedents and consequents share the same modal flavor (they do not, despite traditional assumptions).
\end{abstract}

*This paper is to appear in the proceedings of the "Time and Modality" roundtable held in Paris in December of 2005. I would like to thank the Jacquelines Lecarme and Guéron, Jean-Daniel Mohier, various English speakers, and the participants at the roundtable. 
The goal of this paper is to argue for a certain way of explaining temporal orientation in conditionals. We will limit ourselves to indicative English will conditionals, such as the one in (1).

If Zoe gets cranky, Tasha will get cranky.

By "temporal orientation," I mean the temporal location of the antecedent eventuality (here, the Zoe-get-cranky event) with respect to the utterance time, and similarly the temporal location of the consequent eventuality (here, the Tasha-get-cranky event) with respect to the utterance time. We will also be interested in how these eventualities are situated with respect to each other.

We can articulate this goal a little more precisely. In the above example, let's agree that Zoe get cranky is the "antecedent" (rather than if Zoe gets cranky), and that Tasha get cranky is the "consequent" (rather than Tasha will get cranky; the reasons for scoping out will will become clear later). Now, let us assume that the antecedent and consequent each take a temporal argument. Let $\mathrm{t}^{*}{ }_{\text {ant }}$ be the temporal argument of the antecedent it will normally be equal to $t_{u}$, the utterance time - and let $\mathrm{t}^{*}$ cons be the temporal argument of the consequent. Finally, we define t-sit ${ }_{\text {ant }}$ as the run time of the eventuality in the antecedent (cf. Klein's "situation time"), and similarly define t-sit ${ }_{\text {cons }}$. Then the goal of this paper is to explain how to relate $\mathrm{t}$-sit ${ }_{\text {ant }}$ to $\mathrm{t}^{*}$ ant and $\mathrm{t}-\mathrm{sit}_{\text {cons }}$ to $\mathrm{t}^{*}$ cons , and furthermore, to determine how the antecedent is temporally related to the consequent. We must be coy about this latter point until we know more, since at the outset, it is not immediately clear which antecedent time might be related to which consequent time, though it is clear enough that the antecedent and consequent are somehow temporally related. In the end, we will not have much to say about this issue, though we will need to say something in order to determine what $\mathrm{t}^{*}{ }_{\text {cons }}$ is.

We will see that eventuality type - whether something is eventive or stative - correlates with temporal orientation - whether a t-sit is future-oriented or present-oriented with respect to its $t^{*}$ (i.e., the temporal argument of its clause). This result will render inadequate the "present eventive constraint," which is the accepted way to explain temporal orientation in modal contexts. We will instead justify (though not provide) a different kind of explanation, based on a correlation with modal flavor. It turns out that metaphysical modal flavor correlates with eventivity, and epistemic modal flavor correlates 
with stativity. This result also makes the prediction that antecedents have a modal flavor independently of their consequent, which is true, though such judgments have been oddly overlooked in earlier literature.

\section{UFOs and other oddities}

In this section we will see what the apparent temporal relations are between each $t^{*}$ and its corresponding t-sit, and also give a description of how the antecedent and consequent are temporally related.

We begin with antecedents. Our starting point is a phenomenon that I will be calling "unexpected future orientation," or "UFO" for short. The antecedent in (2a) below is considered to have a UFO because it has future orientation of $\mathrm{t}$-sit ${ }_{\text {ant }}$ with respect to $\mathrm{t}_{u}$ (and since we presume $\mathrm{t}^{*}{ }_{\text {ant }}$ to be equated with $t_{u}$, there is also future orientation of $t$-sit ant with respect to $\left.\mathrm{t}^{*}{ }_{\text {ant }}\right)$ - but there is no obvious morphology to mark the futurity. Indeed it is impossible ${ }^{1}$ to assert the material in the antecedent by saying $(2 \mathrm{~b})$.

a. If it rains tomorrow, Max will get sick.

b. \#It rains tomorrow.

This contrast does not appear in languages universally. The morphological equivalent of (2b) in many languages is perfectly acceptable; (3), for instance, is acceptable in German.

$$
\begin{aligned}
& \text { Es regnet morgen. } \\
& \text { it rains tomorrow } \\
& \text { 'It's going to rain tomorrow.' }
\end{aligned}
$$

Thus in a language like German, one would never be surprised by future orientation in antecedents using the same morphology. But in English, (3a)

\footnotetext{
${ }^{1}$ It is true that a future event time is possible with a simple present verb in English, if the verb phrase describes an event that is scheduled ahead of time or otherwise predetermined.

(i) Zoe plays chess with Xander tomorrow.

The status of these "futurate" readings will become relevant once we have a theory of the type proposed in this paper. For now, we will not attempt an explanation of these readings (but for the classic treatment see Dowty (1979), and more recently Cipria and Roberts (2001), Copley (2002), and Copley (2004)). We will, however, make reference to futurates again below, in the discussion about "settled eventives".
} 
is good and $(3 \mathrm{~b})$ is bad, and that fact requires explanation. ${ }^{2}$

The UFO we have just seen in (3a) has an eventive predicate. Eventive predicates in antecedents must be future-oriented (FO), and cannot be present-oriented (PO), as shown in (4):

(4) If it rains, Max will get sick.

$\neq$ 'If it's raining right now, Max will get sick.' $\quad *$ PO reading

The situation is a little different when the antecedent has a stative verb phrase as in (5).
a. If John is sick tomorrow, Celeste will get sick.
ant. FO
b. If John is sick right now, Celeste will get sick.
ant. PO

The example in $(5 \mathrm{a})$ shows that statives in the antecedent can have UFOs; the example in (5b) shows that they need not. This behavior constrasts with that of eventives, which as we have seen necessarily have UFOs.

This pattern of judgments is familiar from the behavior of complements of (certain) modals (see Condoravdi (2001), Werner (2002)), as in (6). Similarly to the antecedent cases, eventives under modals can only be FO, while statives under modals can be either $\mathrm{PO}$ or $\mathrm{FO}^{3}$

(6) a. Morgan may go. (eventive, only FO; $\neq$ 'may be going')

b. Morgan may be here right now. (stative, PO)

c. Morgan may be here tomorrow. (stative, FO)

It is not so surprising that these environments should behave simiarly to antecedents of conditionals, considering that these are both modal contexts as well. (This common element of modality should also make us wonder what the temporal facts have to do with the modal facts, a question that we will take up again later.)

Consequents of conditionals, which of course are in a modal context as

\footnotetext{
${ }^{2}$ Actually, it is something of a matter of opinion which of (3a) and (3b) requires the explanation. If, based on the facts in other languages, one expects verbs with present (null) morphology to be able to refer to the future, one could instead speak of (3b) as having an "unexpected lack of future orientation." The opposite perspective yields a better acronym, however.

${ }^{3}$ There is another wrinkle here, that of modal flavor, e.g. the examples in (5) have differing possibilities for epistemic, deontic, etc. readings. These will be considered below; for now, we are just interested in the temporal possibilities.
} 
much as antecedents and complements of modals are, behave similarly when it comes to temporal orientation.

To ascertain the temporal orientation of $t_{-}$sit $_{\text {cons }}$ with respect to $\mathrm{t}^{*}{ }_{\text {cons }}$, we will need to know what $\mathrm{t}^{*}$ cons is, i.e., the temporal argument of the consequent. I have mentioned above that the question of how to calculate $\mathrm{t}^{*}$ cons from a time in the antecedent is a tricky one. The answer is different depending on the eventuality type of the antecedent. To begin with, we will hold the eventuality type of the antecedent constant, using only eventive antecedents.

Consider the sentence in (7), for example. What can be said about the temporal relationship between the antecedent and the consequent?

(7) If it rains, Max will get sick.

It appears that the start of the consequent event must begin at least a little bit after the start of the event of the antecedent. ${ }^{4}$ In uttering (7), one conveys that Max gets sick at least a little bit after the rain begins. Indeed, the inference that the rain causes Max to get sick is (at least) difficult to escape, and may well be inescapable. The need for a causal interpretation would definitely explain the temporal observation; for the contextually salient causal mechanism, the rain should indeed start before the illness starts, in order for the rain to cause the illness. For our purposes at the moment, it is enough to note the temporal fact: there must be at least a little rain before the illness begins. ${ }^{5}$

When the consequent is stative, it can be either FO or PO with respect to the start of the antecedent event. Consider the examples in (8), which

\footnotetext{
${ }^{4}$ There are cases where the same event is described in both antecedent and consequent, as in (i):

(i) If Marissa leaves, she will leave quickly.

In such cases, the above generalization does not apply. It is not clear to me when reference to the same event is permitted.

${ }^{5}$ Suppose to the contrary, that one wished to convey that the onset of Max's illness coincides exactly with the onset of the rain. One could say, for example, (ia) or (ib), using when, to convey this.
}

(i) a. It will start raining exactly when Max gets sick.

b. Exactly when it starts raining, Max will get sick.

But one could not truly say (7). For (7) to be true, Max's illness has to start at least a bit after the start of the raining. 
have a stative in the consequent.

(8) a. If John gets mad, Celeste will be mad (afterwards). cons. FO

b. If John gets mad, Celeste will be mad (then). cons. PO

In (8a), where the consequent is future-oriented, John gets mad and then Celeste is mad at some later point. In the reading where the consequent is present-oriented, John gets mad during the time that Celeste is already mad. (These readings have different modal "flavors," which will be considered later.) Thus statives in consequents can be either FO or PO with respect to the relevant time in the antecedent.

This pattern is enough to cause us to posit that $\mathrm{t}^{*}{ }_{\text {cons }}$ in (7) through (8) begins at the same time as the start of t-sit ant. With that assumption, we get the expected relation between $\mathrm{t}^{*}{ }_{\text {cons }}$ and $\mathrm{t}$-sit ${ }_{\text {cons }}$ : when the consequent is eventive, $\mathrm{t}$-sit ${ }_{\text {cons }}$ must be future-oriented with respect to $\mathrm{t}^{*}{ }_{\text {cons }}$ (i.e., it must start at least a little after the beginning of $\mathrm{t}^{*}$ cons $)$, and when the consequent is stative, $\mathrm{t}_{\text {-sit }}{ }_{\text {cons }}$ can be either present-oriented or future-oriented with respect to t* $^{*}$ cons .

The situation is similar when the antecedent is stative and PO, as in (9).

(9) a. If Xander is cranky now, Zoe will get cranky. eventive cons., FO

b. If Xander is cranky now, Zoe will be cranky (now).stative cons., $\mathrm{PO}$

c. If Xander is cranky now, Zoe will be cranky (the next day).stative cons., FO

The familiar pattern is there: eventive consequents must be future-oriented, and stative consequents can be either present-oriented or future-oriented. The data in (9) are also compatible with the idea that $t^{*}{ }_{\text {cons }}$ is constrained to start when t-sit ant starts. But in fact there would be another possible hypothesis if we were just to look at the data in (9) on its own, since in stative PO antecedents, t-sit ${ }_{a n t}$ has to overlap $t^{*}{ }_{a n t}$. So the data in (9) are also compatible with a hypothesis that $\mathrm{t}^{*}{ }_{\text {ant }}$ (not $\mathrm{t}$-sit $\left.{ }_{\text {ant }}\right)$ is what constrains $\mathrm{t}^{*}$ cons.

This alternative hypothesis turns out to be appropriate when the antecedent has additional tense-aspect morphology (that is, it is what Condoravdi calls a "temporal" predicate), as in (10).

(10) If Xander was cranky yesterday, Zoe will be cranky now/\#then/the 
day after tomorrow.

The time in the antecedent that constrains the temporal location of $\mathrm{t}^{*}$ cons cannot be t-sit $t_{\text {ant }}$. If it were, we would expect Zoe's crankiness to be either overlapping t-sit ${ }_{a n t}$ or later than it. But it cannot do this (as shown by the non-acceptability of then); instead, it either overlaps or is later than $t_{u}-$ which we assume has the same value as $\mathrm{t}^{*}{ }_{\text {ant }}$. So the alternative hypothesis, namely that $\mathrm{t}^{*}$ ant is the antecedent time that matters, works here, and the original hypothesis is not appropriate.

Confusingly, the original hypothesis is once again appropriate when the antecedent is a future-oriented stative, again on the assumption that $\mathrm{t}^{*}$ ant is $\mathrm{t}_{u}$ :

(11) If Xander is cranky tomorrow, Zoe will be cranky \#now/then/the next day.

Here, by parallel argumentation to $(10), \mathrm{t}^{*}$ cons cannot have the same value as $t_{u}$, but rather, has to be in the future.

So, to summarize with a question, what can we say about how $\mathrm{t}^{*}{ }_{\text {cons }}$ is related to the antecedent? Only the not-so-pretty picture in (12):

a. Original hypothesis: $\mathrm{t}^{*}{ }_{\text {cons }}$ begins when $\mathrm{t}$-sit ${ }_{\text {ant }}$ begins.

Accounts for eventive antecedents and future-oriented stative antecedents.

Compatible with present-oriented stative antecedents.

b. Alternative hypothesis: $\mathrm{t}^{*}$ cons begins when $\mathrm{t}^{*}{ }_{\text {ant }}$ begins.

Accounts for temporal antecedents.

Compatible with present-oriented stative antecedents.

It is important to remember that even with this complex picture, there is one clear result: Consequents behave just like antecedents (and like the complements of modals) in relating their $t^{*}$ to their t-sit: With eventive consequents, $\mathrm{t}$-sit cons $_{\text {s }}$ is future-oriented with respect to $\mathrm{t}^{*}{ }_{\text {cons }}$, and with stative consequents, $\mathrm{t}_{\text {-sit }}{ }_{\text {cons }}$ can be either present-oriented or future-oriented with respect to $\mathrm{t}^{*}{ }_{\text {cons. }}{ }^{6}$

Incidentally, the existence of this pattern for both the antecedent and consequent of will conditionals suggests that will contributes no extra future or non-past tense meaning of any kind to the relationship between $t^{*}$ and

\footnotetext{
${ }^{6}$ Temporal predicates, of course, further alter the relationship between $\mathrm{t}^{*}$ and $\mathrm{t}$-sit.
} 
t-sit in the consequent - at least, none that it does not also contribute to the antecedent. There are at least two ways we might account for this fact: will might take wide scope, or it might mark agreement with a null modal that takes wide scope. Either way is fine; I will assume the first.

We now have the basic facts about the relation between $t^{*}$ and $t$-sit in both antecedents and consequents. We also know that these facts hinge on the eventuality type of the antecedent and consequent: eventives must be FO, while statives can be either FO or PO. Our next move is not to explain these facts, but first, to dismantle a popular type of explanation for these facts. After that, we will interest ourselves in the possibility of a different kind of explanation for temporal orientation within the antecedent and consequent, one that makes reference to modal flavor.

\section{Away from an explanation}

Given that we see the same relationship between $t^{*}$ and t-sit in antecedents, complements of modals, and consequents - i.e., in modal contexts - it is reasonable to think that it is all for the same reason. The most reasonable reason to propose, and one that has often been proposed for such situations, is what we will be calling the "present eventive constraint" (PEC). It says that both $\mathrm{FO}$ and $\mathrm{PO}$ readings are in principle possible, but that eventive FO readings are alone in being ruled out. However, we will see that the $\mathrm{PEC}$ is not in fact the right way to deal with these environments, since a key assumption motivating the PEC is not valid. This development will make us rethink it as an explanation for this pattern.

We have just seen that t-sit in a modal context can apparently be either $\mathrm{PO}$ or FO with respect to the $\mathrm{t}^{*}$. Consider the matrix will sentences below in (13). It is clear that t-sit can be PO with respect to $t_{u}$, as in (13a), or FO with respect to $t_{u}$, as in $(13 \mathrm{~b}) .^{7}$

$$
\begin{aligned}
& \text { a. Zoe will be cranky (right now). } \\
& \text { b. Zoe will be cranky at } 4 \text { tomorrow. }
\end{aligned}
$$$$
\text { "epistemic will;" } \begin{array}{r}
\mathrm{PO} \\
\text { FO }
\end{array}
$$

\footnotetext{
${ }^{7}$ Some readers may look at (i) and see a modal, epistemic will in (ia), and a non-modal, future tense will in (ib). Instead of treating (ib) as having a future tense, we are treating it as having a modal with metaphysical modal flavor. See Condoravdi (2003) for arguments motivating a unitary modal analysis of will. In any case, at the moment we are concerned with the difference in the temporal orientation of the eventualities in (ia) and (ib), though the difference in modal flavor will come to be relevant towards the end of the paper.
} 
Note that (14), which lacks a temporal adverbial, sounds somewhat incomplete when it has an intended future orientation, or as if the temporal specification must be somehow understood from the context.

Zoe will be cranky.

This need for a temporal adverbial is commonly referred to as "anchoring." Anchoring can be accomplished in a number of ways: with a temporal adverbial as in (15a), with a when clause as in (15b), or with an if clause, as in $(15 \mathrm{c})$. (The if clause does something else modal in addition to providing a temporal anchor, of course, but the point here is that it does provide the temporal anchoring.)

a. At 4, Zoe will be cranky.

b. When you see Zoe, she will be cranky.

c. If you see Zoe, she will be cranky.

So anchoring must do what (we decided in the last section) the eventive antecedent does: It shifts forward the $\mathrm{t}^{*}$ of Zoe be cranky. (For reasons discussed above, we can assume in all cases that will takes wide scope.)

We can confirm that it is $\mathrm{t}^{*}$ and not $\mathrm{t}$-sit that is shifted forward by considering a temporal predicate, that is, one with temporal-aspectual morphology, as in (16):

(At 4/When you see Zoe/If you see Zoe), she will have been cranky.

In the sentence in (16), what is shifted forward is the time that is the argument of Zoe have been cranky, not the time of the crankiness itself (which, according to the meaning of the future perfect, could take place before the anchor). This is additional evidence that the time being anchored is not t-sit, but is rather $t^{*}$.

So t-sit in (14) is FO with respect to $t_{u}$ exactly when $t^{*}$ is shifted forward by an anchor: It can be shifted forward contextually, or with a temporal adverbial, or with a when-clause, or with an if clause. But if these "anchors," essentially reference time shifters, are absent, t-sit must be PO with respect to $\mathrm{t}_{u}$.

This need for anchoring has two important corollaries for us. The first is that $\mathrm{t}^{*}$ is not always the same as $\mathrm{t}_{u}$; it can be shifted forward into the future. The second is that t-sit is always PO with respect to $t^{*}$. Because if it were allowed to be FO with respect to its $t^{*}$, the sentence in (16) could 
have a FO reading in the absence of an anchor, as eventives do. To see the contrast, compare the sentence in (14) (repeated below as (17a)) with that in $(17 b)$ :

a. Zoe will be cranky.

b. Zoe will leave.

In (17a), there is a strong feeling that a contextually-specified time is needed (i.e., an anchor) if the sentence is to be read with future orientation of t-sit with respect to $t_{u}$. In $(17 \mathrm{~b})$, on the other hand, there is future orientation of t-sit with respect to $t_{u}$ even though there is no anchoring. This indicates that $t$-sit in $(17 b)$ really is $\mathrm{FO}$ with respect to $\mathrm{t}^{*}$, and $\mathrm{t}^{*}$ is to be identified with $\mathrm{t}_{u}$.

We have seen that it is possible to shift the $t^{*}$ of an eventive clause forward in at least one case. The $t^{*}{ }_{\text {cons }}$ is shifted forward by an eventive antecedent, as in (18) below.

If it rains, Max will get cranky.

So there is one future shift for $\mathrm{t}^{*}$ cons with respect to $t_{u}$, accomplished by the antecedent, and a second one for $t$-sit ${ }_{\text {cons }}$ with respect to $t^{*}{ }_{\text {cons }}$, accomplished by the eventive itself. This second shift is exactly what statives cannot do.

Interestingly, it's quite difficult to shift the reference time for eventives with temporal adverbials. There seems only to be one shift into the future in (19); the getting cranky seems to have to be at 4 .

At 4, Max will get cranky.

So in (19), $t^{*}$ is apparently shares the same value with $t_{u}$, and at 4 characterizes t-sit, even though it is pronounced at the beginning of the sentence. ${ }^{8}$ For now, it is puzzling why this should be so; we will return to this case later.

We have so far considered stative predicates in complements of will and in consequents of will conditionals. We have seen in these cases that when the t-sit is FO with respect to $t_{u}$, it cannot be because t-sit is FO with respect to $\mathrm{t}^{*}$, but must be because $\mathrm{t}^{*}$ is $\mathrm{FO}$ with respect to $\mathrm{t}_{u}$; t-sit is always $\mathrm{PO}$ with respect to $t^{*}$. This behavior contrasts with that of eventives, in which t-sit is always FO with respect to $t^{*}$ (but as with statives, $t^{*}$ may or may

\footnotetext{
${ }^{8}$ Syntactically, what this would mean is that the temporal adverbial at 4 in (19) is interpreted in the vP, and cannot be interpreted up high.
} 
not be PO with respect to $t_{u}$.) We can represent these generalizations as in (20) and (21), borrowing the neo-Reichenbachian notation in which " $\mathrm{t}_{1}$, $t_{2}$ " denotes present orientation of $t_{2}$ with respect to $t_{1}$ (or equivalently, of $t_{1}$ with respect to $t_{2}$ ), and " $t_{1}-t_{2}$ denotes future orientation of $t_{2}$ with respect to $t_{1}$.

\section{Statives:}
a. $t_{u}, t^{*}, t-s i t$
e.g., Zoe will be cranky now.
b. $\quad t_{u}-t^{*}, t-s i t$
e.g., Zoe will be cranky at 4 .
c. Not POSSIBLE: $t_{u}, t^{*}$ - t-sit

Eventives:
a. $t_{u}, t^{*}$ t-sit
e.g., Zoe will leave.
b. $t_{u}-t^{*}-t-s i t$
e.g., If Max shows up, Zoe will leave (only possible with when or if anchors)

For further evidence for these generalizations, let us consider the behavior of antecedents. Stative antecedents behave as expected. Without an (overt or contextual) adverbial to anchor the stative, $\mathrm{t}_{\text {-sit }}$ ant is $\mathrm{PO}$ with respect to $\mathrm{t}_{u}$, but with an adverbial to fix a time in the future, t-sit ${ }_{\text {ant }}$ is $\mathrm{FO}$ with respect to $\mathrm{t}_{u}$.
a. If Zoe is cranky, ...
PO (FO with context)
b. If Zoe is cranky at 4 tomorrow, ...
c. If, when you see her, Zoe is cranky, ...

As before, the need for the anchor to shift $t^{*}$ forward is evidence that t-sit is not allowed to shift forward on its own. ${ }^{9}$

For eventive antecedents, as before, $\mathrm{t}_{\text {-sit }}$ ant is normally $\mathrm{FO}$ with respect

\footnotetext{
${ }^{9}$ Under what conditions is $t^{*}$ allowed to shift forward? The examples in (i) seem to indicate that will (or presumably, another modal) must be in the consequent:

(i) a. If John is cranky tomorrow at 4, Mary will be happy.

b. \#If John is cranky tomorrow at 4, Mary is happy.

This is further evidence that will has to take wide scope in all the conditionals we have been looking at. It is also reminiscent of theories in which will is a non-past tense, since will here shifts $\mathrm{t}^{*}$ (as we might expect of a tense) rather than t-sit (as we would expect of aspect). Of course some modal element is required too in order to get the conditional semantics; I assume that will contains the modal element, though nothing in particular hangs on that assumption here.
} 
to $t_{u}$ even without an adverbial as in (23a), and this does not change with a temporal adverbial, as in (23b). But, with a when clause, we get the double future orientation; the onset of the sleep in (23c) must be after the onset of your seeing Zoe.
a. If Zoe falls cranky, ...
b. If Zoe falls cranky at 4 tomorrow, ...
c. If, when you see her, Zoe falls cranky, ...

This behavior is exactly what we expect.

So both stative and eventive predicates can have a $t^{*}$ that is $\mathrm{PO}$ or FO with respect to $t_{u}$. But eventives always have a t-sit that is $\mathrm{FO}$ with respect to $\mathrm{t}^{*}$, and statives always have a $\mathrm{t}$-sit that is $\mathrm{PO}$ with respect to the reference time. But if this is always true, then we have no "real" FO statives - that is, no statives that can shift forward by themselves. They only shift forward because of an independent mechanism that allows a future shifting of $t^{*}$, a process that is common to eventives as well.

What do these facts mean for the present eventive constraint?

We began by noting that it was possible to have future orientation of t-sit with respect to $t_{u}$ in antecedents (these were the "UFOs"), and more generally under modals and in consequents, without any obvious future-orienting morphology. Since it is obligatory for eventives, and optional for statives, the traditional response to this fact has been to generally rule in both present and future orientation of t-sit with respect to $t_{u}$. Then it is just PO eventives that need to be ruled out. These were ruled out by some version of a "present eventive constraint" (PEC).

But now we see that, if more attention is paid to $t^{*}$ - which can be either present- or future-oriented itself with respect to the $t_{u}$ - it is clear that the relationship between $t$-sit and $t_{u}$ should be broken down into two relationships, one between $t_{u}$ and $t^{*}$, and one between $t^{*}$ and $t$-sit. Once we do that, we can conclude that eventives always have a t-sit that is $\mathrm{FO}$ with respect to $t^{*}$, and statives always have a t-sit that is $\mathrm{PO}$ with respect to $\mathrm{t}^{*}$. But now it is unsatisfactory to have one constraint to rule out PO eventives and another constraint just to rule out FO statives; two constraints to rule out two of four possibilities is arguably too much theoretical machinery.

Moreover, it is not even clear how we would justify a "future stative constraint." The usual explanation for the PEC goes like this: Eventives can not be evaluated at the present moment because the present moment is 
homogenous, and cannot have an event take place during it. ${ }^{10}$ Can such an explanation be extended to account for a putative FSC, i.e., to explain why statives might not be evaluated except at their input time? At this point, it is hard to think of how it could be.

Thus the PEC is really not worth pursuing further as an explanation for UFOs and other temporal orientation facts in conditionals and other modal contexts; it cannot explain the unexpected lack of future orientation for statives. But fortunately, there is something associated with present orientation and future orientation that we can mine for an explanation: namely, modal flavor. We now, therefore, turn our expectant hopes towards the possibility of a modal explanation for the temporal facts.

\section{Towards an explanation}

In (24a) below, a prediction is made that has the flavor of being about how the world turns out, whether we get to check and see it or not. We will refer to this as a "metaphysical flavor;" Zoe's actually getting cranky is FO with respect to the utterance time. In (24b), however, the prediction has the flavor of being about what is true now (PO), and there is a suggestion, perhaps, that we are about to check whether that is so. If anything about the situation in (24b) is in the future, it is the finding out, rather than Zoe's being cranky. We will refer to this flavor as an "epistemic flavor."
a. Mary will get cranky tomorrow.
metaphysical; FO
b. Mary will be cranky right now.
epistemic; PO

In this case, the present orientation of $t$-sit with respect to $t^{*}$ is associated with the epistemic flavor, while the future orientation of t-sit with respect to $\mathrm{t}^{*}$ is associated with the metaphysical flavor.

The question now is whether we can connect the temporal orientation facts to something modal. That is, can we say that statives, in addition to always having a t-sit that is $\mathrm{PO}$ with respect to $\mathrm{t}^{*}$, are also always epistemic? And that eventives, in addition to always having a t-sit that is FO with respect to $t^{*}$, are always metaphysical? And having demonstrated both of

\footnotetext{
${ }^{10}$ At any rate, such an explanation needs special pleading to account for the PEC-like effects with future-shifted $t^{*}$, since the future $t^{*}$ is not the present moment, but eventives still must have their t-sit shifted into the future with respect to the $t^{*}$. At the very least, it must be made clear how a future $t^{*}$ might be treated as though it were $t_{u}$.
} 
these, can we give an explanation for the temporal facts that is based on the modal facts?

There is an argument, made by Condoravdi, that if valid would vitiate such a line of reasoning. She argues that there are epistemic eventives. If she is correct, we cannot appeal to modal flavor to explain the correlation between temporal orientation and eventuality type. I will argue now, however, that epistemic eventives do not actually exist. It is not that Condoravdi's examples are not actually epistemic; it is that they are derived statives, and therefore not actually eventive.

\subsection{No real epistemic eventives}

To argue for the existence of epistemic eventives in modal contexts, Condoravdi considers a context where we know that a certain professor will meet with one senior administrator. Then both the discourse in (25) and the discourse in (26) are coherent.

(25) a. It hasn't been decided yet who he will meet with.

b. He may see the dean. He may see the provost.

(26) a. It has been decided who he will meet with but I don't know who it is.

b. He may see the dean. He may see the provost.

Condoravdi's idea is that the sentences in (25b) and (26b) are assertable whether the future-oriented event is not yet settled, as in the context provided by $(25 \mathrm{a})$, or already settled, as in the context provided by (26a). I find that the settled reading can be a bit difficult to get, but the dialogue in (27) highlights that reading.

a. Who does he see tomorrow?

b. Someone. Let's see. Darn, I can't find the book. He may see the dean, he may see the provost. I don't know. Go ask him.

When something is assumed settled, like the identity of the person being seen tomorrow, one can check now to see whether it is true or not (at least, that is what the sentences in question presuppose). That is, what we get when something is settled is epistemic modal flavor. For Condoravdi, it is settledness itself that makes metaphysical modality impossible. However, to stop there is to miss a generalization. Settledness is linked to another 
phenomenon aside from modal flavor, namely the ability to be predicated of the present time, as we will see now. This ability makes "settled eventives" look more like statives.

The sentence in (28a), which has a stative, can describe something that is currently taking place. But (28b) cannot be used to describe something taking place at the present moment.
a. Toby likes the dean. (does describe a current Toby-like-the-dean state)
b. \#Toby sees the dean. (cannot describe a current Toby-see-the- dean event)

In English, if you want to use an eventive verb phrase to refer to current goings on, you can, but the meaning is either habitual, as in (29a), or something very much like Condoravdi's settled case, but without a modal (a simple present futurate), as in (29b).
a. Right now, Toby sees the dean on Mondays.
habitual
b. Right now, Toby sees the dean tomorrow.
simple futurate (like Condoravdi's "settled" case)

The important point here is that the "settled" futurate case in (29b) is fine, just like the habitual in (29a). Also like the habitual, it seems to say something about the utterance time $t_{u}$, even though t-sit is different (i.e., for the habitual, today need not be a Monday for (29a) to be true). ${ }^{11}$ In the habitual case, if it is truly asserted, what is true right now is that Toby has the habit of seeing the dean on Mondays (or perhaps, what is true right now is that

\footnotetext{
${ }^{11}$ In fact, if we consider other things we can do to eventive predicates to form sentences that describe a current state, we can construct parallel examples with may that are also fine.

(i) a. Toby sees the dean on Mondays.

b. Toby is seeing the dean right now.

habitual

c. Toby is seeing the dean tomorrow.

ongoing progressive futurate progressive

(ii) Everyone has a special administrator who they see for advice. He may see the dean, he may see the provost, I don't know.

habitual

(iii) He may be seeing the dean. He may be seeing the provost. ongoing or futurate progressive
} 
there is a rule that compels him to do so). In the futurate case, if it is truly asserted, what is true at $t_{u}$ is that there is a schedule or plan for Toby to see the dean tomorrow. ${ }^{12}$

Both habitual sentences and futurate sentences, then, behave like stative sentences in that they can both be asserted of the present moment.

Now, the work of the PEC in distinguishing eventives and statives is done in Condoravdi's theory by her AT function, given below in (30).

$$
\begin{aligned}
& \operatorname{AT}(t, w, P)=\exists e[P(w)(e) \& \tau(e, w) \subseteq t] \text { if } P \text { is eventive } \\
& =\exists e[P(w)(e) \& \tau(e, w) \circ t] \text { if } P \text { is stative } \\
& =P(w)(t) \text { if } P \text { is temporal }
\end{aligned}
$$

Eventives, treated in the first clause of the definition, are given a run time $\tau$ (i.e., t-sit) that is included in the interval t. Statives, treated in the second clause, have a run time overlapping the interval t. In a matrix clause, the interval t will have the value now, which for these purposes is an interval that begins at the moment of utterance and extends infinitely into the future. ${ }^{13}$

Based on Condoravdi's treatment of the "settled" cases under modals, as in (26b) and (27b) above, how would her theory handle the difference in judgments between (31a), a "settled" or futurate case, and (31b), an ordinary eventive case?

$$
\text { a. Toby sees the dean tomorrow. }
$$

b. \#It rains tomorrow.

Both have present tense, which for Condoravdi is as in (32).

$$
\text { PRES: } \lambda P \lambda w[\operatorname{AT}(n o w, w, P)]
$$

The AT function guarantees that the eventive in both cases is shifted to the future. But what rules out (31b)? Presumably it is that (31b) does not describe a settled event - since we don't normally presuppose it to be settled that it is going to rain tomorrow - while (31a) does describe a settled event. Condoravdi doesn't discuss these cases, and treats settledness as a property that only applies to complements of modals. But let's try to extend

\footnotetext{
${ }^{12}$ See also Copley (2002) and Copley (2004) for how the schedule or plan interacts with the rest of the denotation, as well as Copley (2005) for thoughts on the nature of the schedule or plan.

${ }^{13}$ This function incorporates a version of the PEC, and thus does not address the remarks above about the non-existence of "real" FO statives.
} 
her theory by expanding the notion of settledness to include the non-modal cases, and adding the constraint that assertions can only be about things that are already settled:

For any $\mathrm{P}, \mathrm{w}, \mathrm{t}$ : "P" can be asserted at $\mathrm{w}, \mathrm{t}$ only if $\mathrm{P}$ is settled at $\mathrm{w}, \mathrm{t}$.

This addition may be the simplest one to make to account for the difference between (32a) and (32b). But it is also problematic. We will need to extend the definition of settledness to include temporal predicates, because one does not assert just "P" in this account, but rather "PRES P." There shouldn't be a problem with that. But what about extending the notion of settledness to something with a modal, like will $P$ ? Surely we want to say that sentence such as that in (34) can be asserted.

It will rain tomorrow.

In that case, then, according to the requirement in (33), it should be settled that "will P." But do we really want to say that in order to assert (34), it should be settled that it will rain tomorrow? And that if it is not settled that it will rain tomorrow, that (34) is just as bad as (31b)? One alternative is to define the settledness of will $P$ in some other way to entail that it is assertable even when it is not settled whether $\mathrm{P}$ will happen or not. Another alternative is to relax the requirement in (33) in such a way as to exclude the sentence in (34). But each of these alternatives seems to be quite inconvenient.

This line of inquiry having hit an obstacle, we should wonder if there is anything else we could try, to explain the difference between (31a) and (31b), and account for the future orientation of settled eventives. We noted above that futurate readings and habitual readings do not predicate the event of their reference time. Habituals predicate of the reference time something like lawlike behavior, while futurates predicate of the reference time a current rule or schedule. Thus it makes sense to say that the futurate cases, like the habituals, are really derived statives. It is whatever the futurate semantics is, presumably something ${ }^{14}$ in the semantics of the imperfective, that pushes the occurrence of the event into the future. So when it combines with a

\footnotetext{
${ }^{14}$ If this something is a modal, which seems plausible, then we can return to Condoravdi's idea of settledness as being a property that is only relevant to complements of modals. But this modal would not be an epistemic one, rather one having to do with natural laws/current schedules, so there would still be no epistemic eventives.
} 
modal, as far as the modal is concerned, it is just combining with a stative. And when we assert a futurate, we are asserting a stative of the present, not asserting an eventive of the future.

Additional evidence for this idea comes from the fact that futurate eventive antecedents do not behave like ordinary (non-futurate) eventive antecedents, but rather like stative antecedents, in that the time that enters into a temporal relationship with the consequent is $t^{*}$, not t-sit. Consider the conditional in (35). The antecedent could have a non-futurate reading, in which the speaker will give Mary a call after she actually leaves (and nothing is implied about Mary's current plans), as well as a futurate reading, in which case the speaker is saying she'll give Mary a call as soon as she finds out that she has plans to leave on Monday.

If Mary leaves on Monday, I'll give her a call.

The dialogue in (36) further demonstrates the existence of the futurate reading for the antecedent If Mary leaves on Monday; the addition of today to the consequent in fact rules out the non-futurate reading:

a. I thought Mary was already out of town.

b. No, she leaves on Monday.

c. Oh, well, if Mary leaves on Monday, I'll give her a call today.

The difference between the non-futurate and futurate readings is this. As we saw earlier, with the non-futurate eventive antecedent, the $t^{*}$ cons begins when

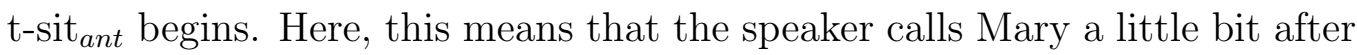
the time when she actually leaves. But with the futurate case, the reference time of the consequent does not start when t-sit ${ }_{a n t}$ starts, but rather, with $\mathrm{t}^{*}$ (or equivalently, with $\mathrm{t}_{u}$ ) starts. In this, it behaves similarly to stative antecedents, discussed above.

If settled eventives are really to be treated as PO statives, the way habituals are treated, there is no more justification for the existence of eventive FO epistemics, and in fact, there is no justification for the existence of any eventive epistemics at all, as eventive PO epistemics clearly do not exist, and so were never at issue. Therefore, all epistemic cases are stative. ${ }^{15}$

\footnotetext{
${ }^{15}$ It is not true, however, that all statives under modals are epistemic. Modals can have deontic flavor with either statives or eventives. For example, either (ia) (eventive) or (ib) (progressive, i.e. derived stative) are possible as injunctions for what Mary is supposed to do:
} 


\subsection{Antecedents have their own modal flavors}

The way is almost clear for us to make the case that the correlation between eventuality type and temporal orientation should be explained in terms of a correlation with modal flavor. Statives have a t-sit that is $\mathrm{PO}$ with respect to their $\mathrm{t}^{*}$, and they are epistemic in modal flavor; eventives have a t-sit that is FO with respect to their $\mathrm{t}^{*}$, and they are metaphysical in modal flavor. One obstacle remains: if modal flavor correlates with eventuality type and temporal orientation in both antecedents and consequents, we would expect an antecedent and a consequent in the same conditional to be able to have different modal flavors from each other. This question is not addressed by Kratzer-style (Kratzer, 1986) possible worlds treatments of conditionals, which assume that a conditional has a single modal flavor (in the absence of overt embedded modals in either clause).

Yet this traditional assumption, surpisingly, is not warranted. As it turns out, antecedents have their own modal flavor, and this modal flavor correlates, as we now expect, with eventuality type and temporal orientation.

How do we test a sentence (or an utterance) for modal flavor? In general, it is necessary to take a native speaker's word for it, as for judgments of felicity or truth. There is, however, a straightforward test for antecedents. ${ }^{16}$ Adding it's true that to the antecedent is good with stative antecedents (which have an epistemic flavor) but bad with eventive antecedents (which have a metaphysical flavor). ${ }^{17}$ The stative antecedent in (37a), even before

(i) a. Mary will sing when the queen walks in.

b. Mary will be singing when the queen walks in.

Under deontic must, as in (iia) and (iib), these possibilities have been called "obligation to do" and "obligation to be" respectively. In (iia) Mary has an obligation to sing, while in (iib) there is a requirement that she be singing at that point.

(ii) a. Mary must sing when the queen walks in.

b. Mary must be singing when the queen walks in.

Even imperatives can occur both with eventives and statives:

(iii) a. Sing when the queen walks in!

b. Be singing when the queen walks in!

I will not consider such cases further here.

${ }^{16}$ Recall that I also argued for a correlation between epistemic modal flavor and the ability to occur on its own without the modal, so that would consitute a test as well.

${ }^{17}$ It's unlikely that I am the first person to notice this, so I would be grateful to hear 
the consequent is heard, has an epistemic flavor, and is fine with it's true that, as shown in (37b).

stative

a. If it's cold out right now, ...

b. If it's true that it's cold out right now, ...

The eventive antecedent in (38a), on the other hand, has a metaphysical flavor, and is not good with it's true that, as in (38b).

eventive

a. If it rains tomorrow, ...

b. \#If it's true that it rains tomorrow, ...

(38b) may be good for certain speakers of philosophical English, but for most speakers it is terrible. Why is (38b) so bad? Let us suppose that \#it rains tomorrow does not express a proposition; therefore it can't be true or false, and can't be asserted.

Anchored stative antecedents (i.e, those with a future-oriented $t^{*}$ ) seem at first blush to behave like eventives, in that they are not possible with "it's true that":

$$
\text { anchored "FO" stative }
$$

a. If it's raining at 4 tomorrow, ...

b. \#If it's true (now) that it's raining at 4 tomorrow ...

There is however a variant of (39b) that is acceptable, namely (40).

(40) If at 4 tomorrow it's true that it's raining (at that time) ...

This has an epistemic flavor as well. These data show that anchored statives are possible, but they are not propositions evaluated at the present moment (because if they were, (39b) would be good). Rather, they are propositions evaluated at the future time provided by the temporal adverbial. This explains why (40) is acceptable, and is exactly the result that was obtained in the earlier discussion of the status of these future-oriented statives: $t^{*}$ ant , the argument of the antecedent proposition, is $\mathrm{FO}$ with respect to $\mathrm{t}_{u}$, and $\mathrm{t}_{\text {-sit }}{ }_{\text {ant }}$ is interpreted as $\mathrm{PO}$ with respect to $\mathrm{t}^{*}{ }_{\text {ant }}$.

about any earlier statements of this fact. 
Note that the anchored stative in (39b) is ruled out for a different reason than the FO eventive in (38b), which is (we suspect) itself ruled out for not being a proposition. This difference is confirmed by the fact that the eventive remains unacceptable in (41), unlike the stative in (40).

(41) \#If at 4 tomorrow it's true that it rains (at that time) ...

So the stative antecedents are things that can be true, either now or at some future $t^{*}$. The FO eventives cannot be true, now or ever, and we thus surmise that they are not propositions at all.

It makes sense that stative antecedents, always $\mathrm{PO}$ with respect to $\mathrm{t}^{*}$ ant, would have an epistemic flavor. The reason is that what one knows has to do (presumably) with which propositions one has added to a set of known propositions as of $t^{*}$. It's not clear yet what the eventive antecedents are perhaps they are predicates of events - but if they are not propositions, as we suspect, we should not be surprised that they invoke a different flavor of modality, one that does not have to do with adding propositions to a set of known propositions.

It is worth confirming that an antecedent and consequent in the same conditional can have different modal flavors, based on their eventuality type. That is, if we look at conditionals of the forms in (42a) and (43a), will they correspond to modal flavors as in (42b) and (43b) respectively?

a. If stative, will eventive $=$ ?

b. If epistemic, will metaphysical

a. If eventive, will stative $=$ ?

b. If metaphysical, will epistemic

We exemplify the combinations we want with the stative predicate be sick and the eventive predicate get sick. (We will stay away from the tricky anchored statives.)

a. If John gets sick tomorrow, Mary will be sick then. $\mathrm{FO}+\mathrm{PO}$

b. If John is sick right now, Mary will get sick tomorrow. $\mathrm{PO}+$ $\mathrm{FO}$

Now, the question is for each of these readings, what modal flavor is possible in the antecedent, and what modal flavor is possible in the consequent? Speakers' judgments are as follows. In (44a), the antecedent supposes that 
something happens (metaphysical flavor), while the consequent conveys that in such a situation, we will find something out that is already the case (epistemic flavor). Conversely, in (44b), the antecedent supposes that we find something out now that is already the case (epistemic flavor), and the consequent then discusses what we are entitled to conclude will happen. In other words: the conditionals in (44) behave as hoped.

Thus, it is official that we need a theory that can specify a different modal flavor for both the antecedent and the consequent; this is the expected result, since the correlation between eventuality type and modal flavor predicts that the antecedent and consequent modal flavors are entirely independent of each other.

More urgently, we need a theory of modality that can actually account for the correlations between modal flavor, eventuality type, and temporal orientation. Moreover, this theory must be able to account for the fact that both kinds of modal flavor can occur in a single conditional, even though epistemic modality apparently has to do with propositions, and metaphysical modality apparently does not.

\section{Conclusion}

At this point we have, I hope, some "proof of concept" that a certain kind of modal theory of temporal orientation in conditionals is an attractive one. To reach this conclusion, I argued that there is a stronger correlation than previously thought between eventuality type and temporal orientation in conditionals, and between both of these and modal flavor. Stativity, present orientation with respect to $\mathrm{t}^{*}$, and epistemic modality are correlated; likewise, eventivity, future orientation with respect to the $t^{*}$, and metaphysical modality are correlated. (We set aside deontic modality, which can occur with both eventives and statives.)

These correlations make the traditional "present eventive constraint" less attractive as a way to explain temporal orientation in conditionals and other modal contexts, since it is not just present-oriented eventives that need to be ruled out, but also future-oriented statives. An explanation of the temporal facts based on the correlation with modal flavor is more attractive, once the objections to this kind of explanation are removed.

An interesting result of this investigation was the finding that antecedents have their own modal flavor, independently from that of the consequent. 
(One upshot is that we can no longer talk about "epistemic conditionals," for instance, unless by that we mean a conditional whose antecedent and consequent are both epistemic.) This is predicted to be true by this viewpoint, because the modal flavor is correlated with the eventuality type of the predicate. The judgments on modal flavor in antecedents corroborate this prediction quite clearly, though oddly, in the mainstream generative linguistic literature, the modal flavor of the antecedent has largely passed unnoticed.

\section{References}

Cipria, A. and C. Roberts (2001). Spanish imperfecto and pretérito: Truth conditions and aktionsart effects in a Situation Semantics. To appear in NLS.

Condoravdi, C. (2001). Temporal interpretation of modals. In D. Beaver, S. Kaufmann, B. Clark, and L. Casillas (Eds.), Stanford Papers on Semantics. Palo Alto: CSLI Publications.

Condoravdi, C. (2003). Moods and modalities for will and would. Handout of talk given at the 2003 Amsterdam Colloquium.

Copley, B. (2002). The Semantics of the Future. Ph. D. thesis, MIT. To appear, Outstanding Dissertations in Linguistics, Routledge.

Copley, B. (2004). The plan's the thing: Deconstructing futurates. ms.

Copley, B. (2005). Ordering and reasoning. ms.

Dowty, D. (1979). Word meaning and Montague Grammar. Dordrecht: Reidel.

Klein, W. (1997). Time in Language. New York: Routledge.

Kratzer, A. (1986). Conditionals. In Papers from the Regional Meetings, Chicago Linguistic Society, pp. 1-15.

Werner, T. (2002). Deducing the future. In Proceedings of NELS 33. 